\section{Genetical Evidence for Synthesis of Transferrin in the Fotus}

CLear-CUT evidence that the foetus synthesizes its own plasma proteins is scant. It has been demonstrated by in vitro experiments that the liver of a foetus of three months gestation can incorporate glycine labelled with carbon-14 into proteins resembling albumin, $\alpha_{1}$-globulin, $\alpha_{2}$-globulin, and $\beta$-globulin of human plasma. These investigations also showed that metal-binding $\beta$-globulin (presumably transferrin) was capable of being synthesized by foetal liver. Other workers have established that the foetus synthesizes haptoglobin by finding some new-born children with types of haptoglobin that were absent in their mothers ${ }^{2,3}$.

In the course of a survey of 212 cord blood sera by starch-gel electrophoresis, genetical evidence was obtained indicating that the foetus produces its own transferrin.

The sera, each with sufficient hærmoglobin added to saturate the haptoglobin completely, were tested by Smithies's technique of starch-gel electrophoresis ${ }^{4}$, using Poulik's discontinuous buffer system ${ }^{5}$. The resultant gels were sliced horizontally, one half stained with amido black $10 B$ to identify protein bands, and the other half with a dilute benzidine stain to locate the haptoglobin-hæmoglobin complexes ${ }^{6}$.

Three of the 212 cord sera contained two protein bands in the transferrin region. The faster migrating of these two bands corresponded to the usual transferrin designated as $C$. In each case, the mobility of the slower-migrating band was identical to that of the $D_{1}$ transferrin of a reference standard. These three new-born children were therefore of the heterozygous transferrin type $C / D_{1}$. The remaining 209 cord blood sera contained only one band in the transferrin region, which had the mobility of $C$ transferrin. These newborns were considered to be homozygous $(\operatorname{Tr} C / C)$. Two of the $\operatorname{Tr} C / D_{1}$ new-born children were negroes, while the third was of Caucasian ancestry. Other examples of slow-migrating transferrins (which as a

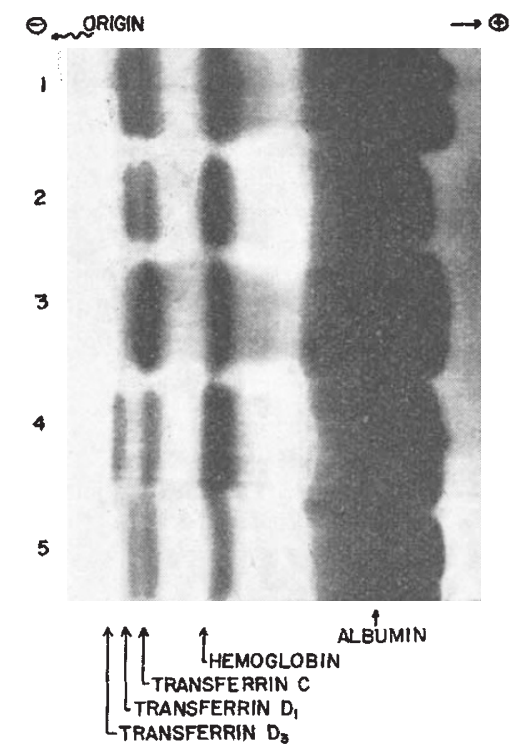

Fig. 1. Portion of starch-gel electrophoretic patterns of family with new-born of $\operatorname{Tr} C / D_{1}$ pattern, run in parallel with reference standards. 1, New-born, $\operatorname{Tr} C / D_{1}$; 2 , reference standard, $\operatorname{Tr} C / D_{1}$; 3, mother, $\operatorname{Tr} C / C ; 4$, reference standard, $\operatorname{Tr} C / D_{3} ; 5$, father,
$\operatorname{Tr} C / D_{1}$ group are designated ' $D$ ' transferrins) have been found in negro populations and Australian aborigines ${ }^{6}$. The three mothers of the $\operatorname{Tr} C / D_{1}$ new-born children had the usual, homozygous transferrin type $(\operatorname{Tr} C / C)$, while their husbands were all heterozygous $\left(\operatorname{Tr} C / D_{1}\right)$ (Fig. 1). In one of the negro families and in the Caucasian family, autoradiography with iron-59 performed ${ }^{7}$ on fresh sera of the infants and their parents verified that the presumptive transferrin bands were truly iron-binding. Since each of the three mothers lacked the $D_{1}$ transferrin, it is evident that transplacental passage from mother to foetus could not account for the $D_{1}$ transferrin in the cord blood, and consequently these new-born children must bave synthesized the $D_{1}$ transferrin themselves.

We thank Dr. Eloise Giblett, of Seattle, Washington, for supplying us with $\operatorname{Tr} C / D_{1}$ and $\operatorname{Tr} C / D_{3}$ reference stendard sera. This work was supported by grants from the John A. Hartford Foundation, Inc., and the National Heart Institute $(H-4706)$.

\section{A. R. RAUSEN \\ P. S. Geralid \\ L. K. Dramond}

Department of Pediatrics,

Harvard Medical School, and

Department of Medicine,

Children's Hospital Medical Center, Boston.

${ }^{1}$ Dancis, J., Braverman, N., and Lind, J., J. Clin. Invest., 36, 398 (1957).

${ }^{2}$ Galatius-Jensen, F., Proc. Sixth Europ. Cong. Homat., 269 (1957).

Rausen, A. R., Gerald, P. S., and Diamond, L. K., Nature, 181, 717 (1961).

- Smithies, O., Biochem. J., 61, 629 (1955).

s Poulik, M. D., Nature, 180, 1477 (1967).

- Smithies, O., Adv. Protein Chem., 14, 65 (1959).

"Giblett, E. R., Hickman, C. G., and Smithies, O., Nature, 188, 1589 (1959).

\section{IMMUNOLOGY}

\section{Rapid Preparation of Fluorescent Anti- bodies using Gel-Filtration}

Is the preparation of fluorescent antibodies the excess dye is generally removed by dialysis for 5-6 days (ref. 1). In order to avoid a time-consuming dialysis and to decrease the risk of destroying antibody activity we have used gel-filtration ${ }^{2}$ in the preparation of a number of fluorescent antibodies, the titres of which were afterwards compared with those of dialysed samples. A preliminary report of the method has already been published ${ }^{3}$.

After the conjugation of serum or a serum fraction with fluorescein isothiocyanate (Sylvana Chemical Co., Orange, New Jersey) as described by Riggs et al. ${ }^{4}$, one portion was dialysed for six days at $2^{\circ} \mathrm{C}$. against a saline-phosphate buffer $(0.15 \mathrm{M}$ sodium chloride in $0.01 M$ phosphate, $p H$ 7.0) with two daily changes, and another portion was subjected to gel-filtration. One ml, of fluorescein-treated material was put on a $2 \times 5 \mathrm{~cm}$. column of gel-filter substance 'Sephadex G-25' (AB Pharmacia, Uppsala, Sweden), previously washed with the saline-phosphate buffer. During elution, which was performed with the same buffer, two yellow zones appeared. The fast-moving one contained the conjugated proteins, while the unbound dye was retarded partly by the gel-filtering effect and partly by adsorption to the 'Sephadex'. The strongly coloured protein fraction was collected and used for the subsequent comparison with the material prepared by dialysis. Generally, a two-fold dilution 